\title{
Modeling and optimization of laser cutting operations
}

\author{
Mohamed Hassan Gadallah ${ }^{1, *}$ and Hany Mohamed $\mathrm{Abdu}^{2}$ \\ 1 Mechanical Design \& Production Engineering Department, Faculty of Engineering, Cairo University Egypt, 12316 Cairo, Egypt \\ 2 Production Engineering \& Design Department, Faculty of Engineering, Minia University, 61516 Minya, Egypt
}

Received 4 June 2015 / Accepted 22 August 2015

\begin{abstract}
Laser beam cutting is one important nontraditional machining process. This paper optimizes the parameters of laser beam cutting parameters of stainless steel (316L) considering the effect of input parameters such as power, oxygen pressure, frequency and cutting speed. Statistical design of experiments is carried in three different levels and process responses such as average kerf taper $\left(T_{\mathrm{a}}\right)$, surface roughness $\left(R_{\mathrm{a}}\right)$ and heat affected zones are measured accordingly. A response surface model is developed as a function of the process parameters. Responses predicted by the models (as per Taguchi's $\mathrm{L}_{27} \mathrm{OA}$ ) are employed to search for an optimal combination to achieve desired process yield. Response Surface Models (RSMs) are developed for mean responses, S/N ratio, and standard deviation of responses. Optimization models are formulated as single objective optimization problem subject to process constraints. Models are formulated based on Analysis of Variance (ANOVA) and optimized using Matlab developed environment. Optimum solutions are compared with Taguchi Methodology results. As such, practicing engineers have means to model, analyze and optimize nontraditional machining processes. Validation experiments are carried to verify the developed models with success.
\end{abstract}

Key words: Optimization, Laser cutting, Kerf width, Taguchi technique, Response surface methodology, Design of experiments

\section{Nomenclature}

$\begin{array}{ll}\text { LBM } & \text { Laser beam machining } \\ \text { RSM } & \text { Response surface methodology } \\ \text { DOE } & \text { Design of experiments } \\ T_{\mathrm{a}} & \text { Kerf taper } \\ R_{\mathrm{a}} & \text { Average surface roughness } \\ \mathrm{Nd}: \mathrm{YAG} & \text { Neodymium:yttrium-aluminum-garnet } \\ \mathrm{S} / \mathrm{N} & \text { Signal to noise ratio } \\ \mathrm{OA} & \text { Orthogonal array } \\ \mathrm{L}_{27} \mathrm{OA} & \text { Orthogonal array of } 27 \text { experiments } \\ \text { ANOVA } & \text { Analysis of variance } \\ \text { ANOM } & \text { Analysis of means } \\ X_{1} & \text { Power } \\ X_{2} & \text { Assist gas pressure } \\ X_{3} & \text { Pulse frequency } \\ X_{4} & \text { Cutting Speed }\end{array}$

\section{Introduction and background}

Laser Beam Cutting (LBC) is an important nontraditional cutting process. It is used to shape engineering materials with complex shapes and strict design and performance functional

*e-mail: mohamed@aucegypt.edu requirements. The process is used for cutting, drilling, marking, welding, sintering and heat treatment processes [1]. Applications of laser sheet cutting include aerospace, automobile, shipbuilding, electronic and nuclear industries. The intense laser light is capable to melt almost all materials [2]. Laser cutting is a thermal energy based non-contact process, therefore does not require special fixtures and jigs to hold the work piece. In addition, it does not need expensive or replaceable tools to produce mechanical force that can damage thin, intricate and delicate work pieces [3]. The effectiveness of laser cutting depends on the thermal, optical and mechanical properties of materials. Therefore, materials with high degree of brittleness, hardness and favorable thermal properties (low thermal diffusivity and conductivity) are suitable for laser cutting operations [4]. High speed steels, ceramics, composites, diamonds, plastics and rubber are typical candidate materials.

Nd:YAG (Neodymium:yttrium-aluminum-garnet) and $\mathrm{CO}_{2}$ are the most widely used laser applications [9]. Nd:YAG laser is an optically pumped solid state laser, working at a wavelength of $1.06 \mu \mathrm{m} . \mathrm{CO}_{2}$ laser is an electrically pumped gas laser that radiates at wavelength of $10.6 \mu \mathrm{m}[2,4] . \mathrm{CO}_{2}$ laser is used in fine cutting of sheet metals at high speeds as it has high average beam power, better efficiency and good beam 
Table 1. Chemical composition of stainless steel (316L) (wt.\%).

\begin{tabular}{lccccccc}
\hline $\mathrm{Ni}$ & $\mathrm{Cr}$ & $\mathrm{C}$ & $\mathrm{Mn}$ & $\mathrm{Si}$ & $\mathrm{S}$ & $\mathrm{Mo}$ & $\mathrm{P}$ \\
\hline $10 \%$ & $16 \%$ & $0.03 \%$ & $2 \%$ & $0.75 \%$ & $0.03 \%$ & $2-3 \%$ & $0.045 \%$ \\
\hline
\end{tabular}

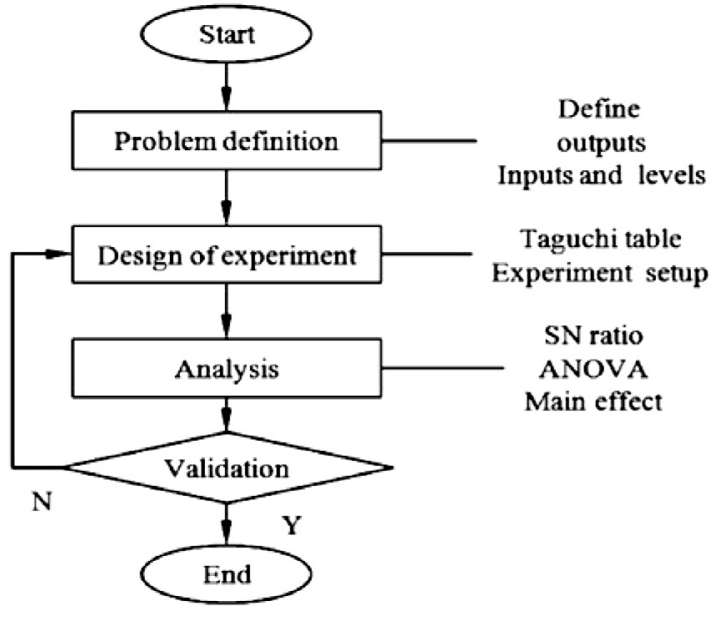

Figure 1. Procedure of Taguchi method [15].

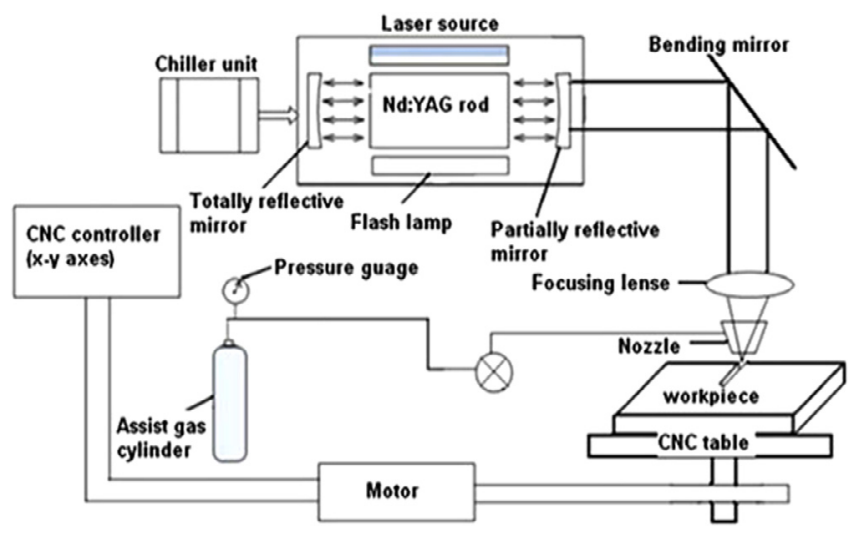

Figure 2. Laser cutting machine utilized in this study.

quality. Nd:YAG laser has low beam power operating in pulsed mode. High peak power is capable to cut thicker materials for different applications [5]. Due to shorter wavelength of Nd:YAG laser, it is reflected to a lesser extent by metallic surfaces and high absorptivity of Nd:YAG laser cutting highly reflective materials with relatively less power [6]. Therefore, $\mathrm{Nd}$ :YAG laser is suitable for processing of metals in general and reflective materials in particular. Gases employed include oxygen, nitrogen and argon. A similar study is carried on $\mathrm{Ni}$ base super alloys [7].

Austenitic stainless steel (316L) is an anti-corrosive and anti-staining materials [8]. The alloy form of stainless steels is milled into coils, sheets, plates, bars, wire, and tubes. Typical applications include food preparation equipments (particularly in chloride environments), pharmaceuticals, marine, architectural, medical implants (orthopaedic implants like total hip and knee replacements) and fasteners. Grade 316 is the standard molybdenum-bearing grade, secondary to 304 amongst the austenitic stainless steels. The molybdenum gives 316 better overall corrosion resistant properties than Grade 304, particularly pitting and crevice corrosion in chloride environments. Grade 316 (with low carbon is immune from sensitization due to grain boundary carbide precipitation). Thus, it is extensively used in heavy gauge welded components $(\geq 6 \mathrm{~mm})$. There is no significant price difference between 316 and 316L stainless steel. The austenitic structure gives these grades excellent toughness, even down to cryogenic temperatures. Compared to chromium-nickel austenitic stainless steels, 316L stainless steel offers higher creep, stress to rupture and tensile strength at elevated temperatures. Some authors studied $\mathrm{CO}_{2}$ laser cutting on Kevlar 49 composite materials [19]. Kerf width, dross height and slope of cut are typical process responses. Table 1 gives the chemical composition of 316L stainless steel employed.

The quality of cut depends upon the combination of process parameters such as laser power, type and pressure, cutting speed, sheet thickness, frequency and chemical composition. Researchers have investigated the effect of laser cutting parameters on cut geometry and cut surface quality. They applied one-factor at a time approach to study the effect of process parameters on responses. This approach consumes time and effort for large number of experimental runs because only one factor is varied, keeping all other factors fixed. The interaction effects among various process parameters are not considered which may be of interest in some studies; not to mention higher level interactions.

Li et al. [12] applied Taguchi robust design methodology to study the depth of cut, width of cut and Heat Affected Zone (HAZ) during laser cutting of Quad Flat No-lead (QFN) packages using a Diode Pumped Solid State Laser (DPSSL) system. Three control factors such as laser frequency, cutting speed, and laser driving current contributed greatly to laser cut quality. Tosun and Ozler [13] applied Taguchi methodology for optimization of surface roughness and tool life simultaneously during hot turning of high manganese steel work piece using the sintered carbide tool. The effect of hot turning parameters (cutting speed, depth of cut, feed rate and work piece temperature) on multiple performance characteristics is discussed.

Huehnlein et al. [23] employed design of experiments on the cutting of $\mathrm{Al}_{2} \mathrm{O}_{3}$ ceramic layers. One factor at a time and interaction effects of decision variables are very time consuming. The burr at the kerf is employed as a response for elimination. Process parameters include laser power, cutting speed, distance from nozzle to surface, assist gas pressure, position to the focus and diameter of the nozzle. Velocity and gas pressure prove significant parameters. Forty six experiments are used to carry response surface modeling.

Sharma and Yadava [18] used laser beam cutting for precise cutting of $\mathrm{Al}$ alloy sheet metals. Four process parameters are used to optimize kerf quality (kerf width and kerf deviations) characteristics; these are gas pressure, pulse width, pulse 
Table 2. Input process parameters and levels used in the designed experiments.

\begin{tabular}{llcccc}
\hline Symbol & Input parameters & Unit & Level 1 & Level 2 & Level 3 \\
\hline$X_{1}$ & Power & Watt & 150 & 450 & 750 \\
$X_{2}$ & Oxygen pressure & $\mathrm{MPa}$ & 0.5 & 1 & 1.5 \\
$X_{3}$ & Frequency & $\mathrm{Hz}$ & 25 & 75 & 125 \\
$X_{4}$ & Cutting speed & $\mathrm{cm} / \mathrm{min}$ & 10 & 20 & 40 \\
\hline
\end{tabular}

Table 3. Experimental design using $\mathrm{L}_{27} \mathrm{OA}$.

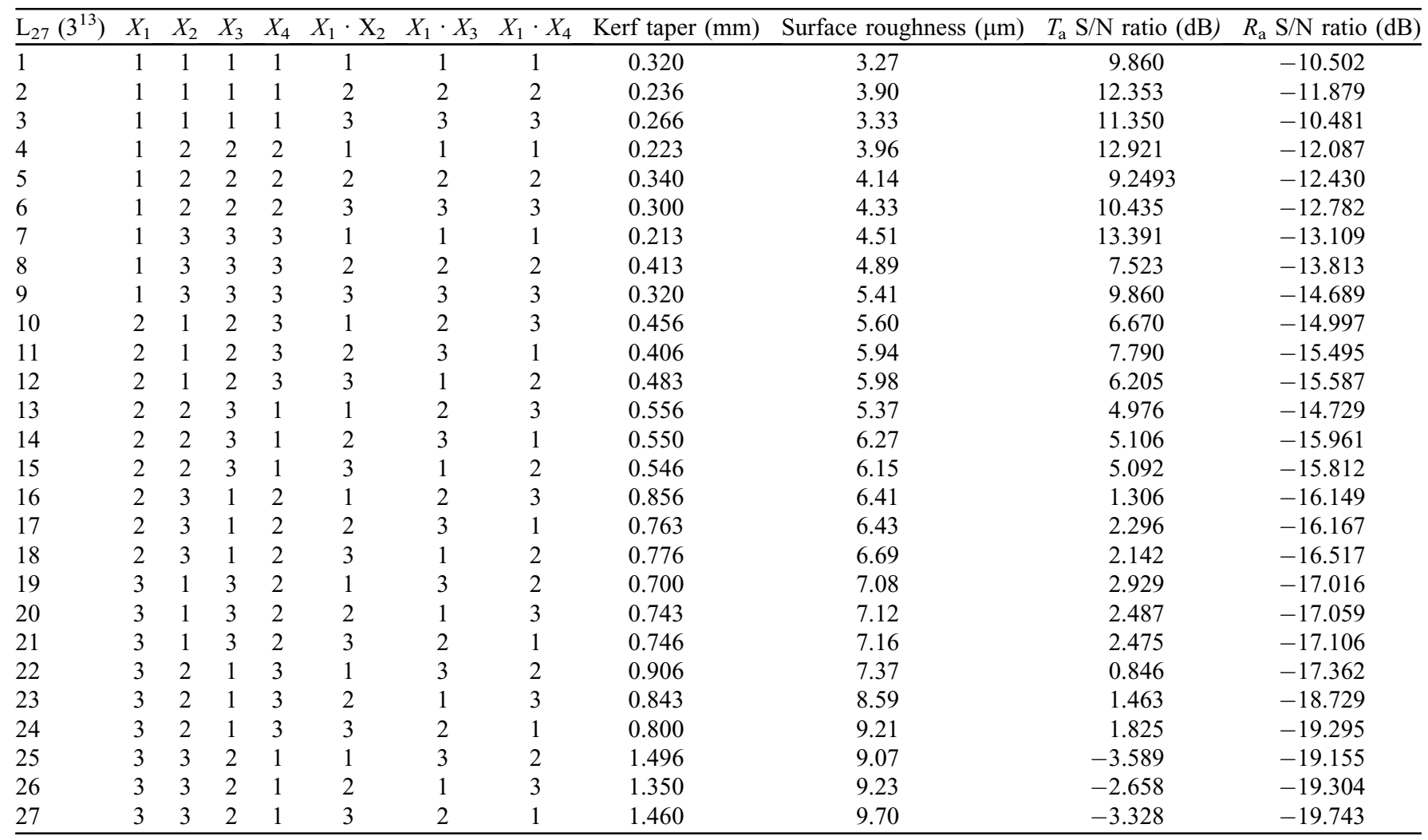
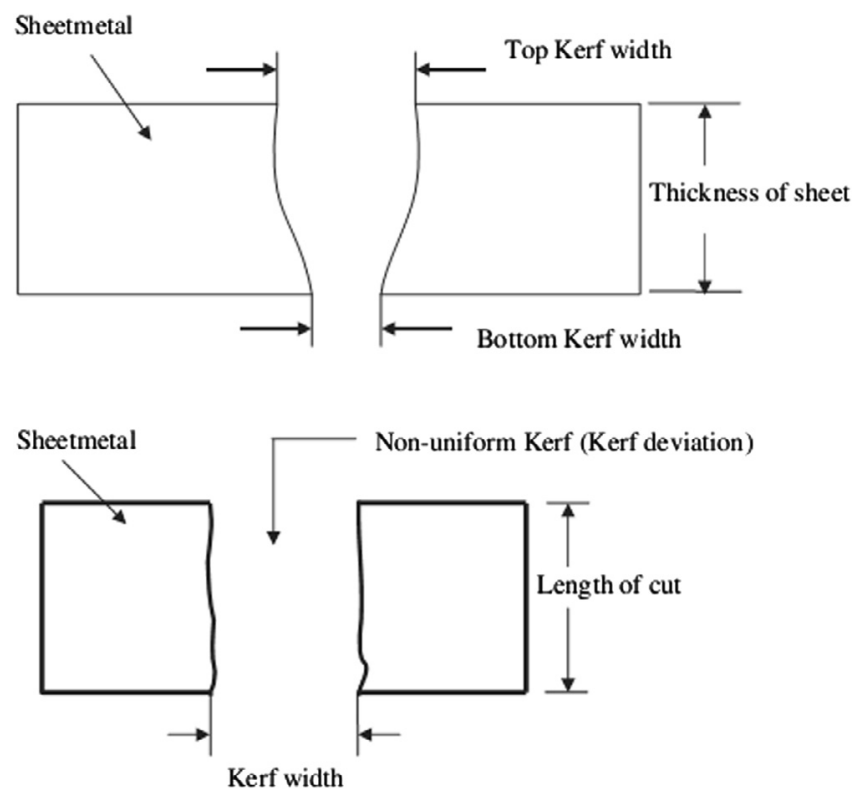

Figure 3. Schematic of laser cut kerf [18]. frequency and cutting speed. Standard orthogonal arrays are used for experimentation. An $\mathrm{L}_{9} \mathrm{OA}$ is employed to host the variations of 4-3 level factors. This means that 2 factors are confounded. Interaction effects can be read in columns 3 and 4 respectively because of degree of freedom requirements [15]. Similar work is reported for Al-Alloy sheets [10].

Brecher et al. [2] developed a novel process concept for Laser Assisted Milling (LAM) with local laser induced material plastification before cutting. Results are presented for Nickle based alloy Inconel 718 using TiAlN coated cemented carbide cutting tool.

Adelmann and Hellmann [24] described a fast algorithm to optimize the laser parameters for laser fusion cutting process. The objective is to obtain a burr free laser cut. The algorithm performs on a one at a time design of experiments basis. Parameters include laser power, focal position and gas pressure. The algorithm is known as Fast Laser Cutting Optimization Algorithm (FALCOA). The study is limited to $1 \mathrm{~mm} \mathrm{Al}$ sheets using a $500 \mathrm{~W}$ single mode fiber laser.

Miroslav and Milos [21] presented a complete review study on $\mathrm{CO}_{2}$ laser cutting with respect to materials employed 
Table 4. Analysis of Variance (ANOVA) for the kerf taper ${ }^{\mathrm{a}}$.

\begin{tabular}{|c|c|c|c|c|c|}
\hline Source & Seq. SS & Df & Adj. MS & $F_{\text {calculated }}$ & $P(\%)$ \\
\hline Power $\left(X_{1}\right)$ & 500.924 & 2 & 250.462 & 74.883 & 79.86 \\
\hline Pressure $\left(X_{2}\right)$ & 72.784 & 2 & 36.392 & 10.880 & 11.61 \\
\hline Frequency $\left(X_{3}\right)$ & $7.797^{*}$ & 2 & & & \\
\hline Cutting speed $\left(X_{4}\right)$ & $15.048 *$ & 2 & & & \\
\hline$X_{1} \cdot X_{2}$ & $0.897^{*}$ & 4 & & & \\
\hline$X_{1} \cdot X_{3}$ & $4.121 *$ & 4 & & & \\
\hline$X_{1} \cdot X_{4}$ & $5.286^{*}$ & 4 & & & \\
\hline Error & 53.516 & 16 & 3.3447 & & 8.53 \\
\hline Total & 627.224 & 26 & & & 100 \\
\hline
\end{tabular}

${ }^{\text {a }}$ Df: degrees of freedom; SS: sum of squares; MS: Variance; $P$ : percent contribution. ${ }^{*}$ Pooled, Tabulated $F$-ratio at $99 \%$ confidence level: $F_{0.01,2,16}=6.23$.

Table 5. Analysis of Variance (ANOVA) for the average surface roughness ${ }^{\mathrm{a}}$.

\begin{tabular}{lcccc}
\hline Source & Seq. SS & Df & Adj. MS & $F_{\text {calculated }}$ \\
\hline Power $\left(X_{1}\right)$ & 156.764 & 2 & 78.382 & 49.173 \\
Pressure $\left(X_{2}\right)$ & 19.067 & 2 & 9.534 & 15.86 \\
Frequency $\left(X_{3}\right)$ & $1.125^{*}$ & 2 & & \\
Cutting speed $\left(X_{4}\right)$ & $2.357^{*}$ & 2 & & 10.28 \\
$X_{1} \cdot X_{2}$ & $3.036^{*}$ & 4 & & \\
$X_{1} \cdot X_{3}$ & $0.123^{*}$ & 4 & & \\
$X_{1} \cdot X_{4}$ & $0.028^{*}$ & 4 & & \\
Error & 28.688 & 16 & 0.6013 & \\
Total & 185.452 & 26 & & 5.19 \\
\hline
\end{tabular}

${ }^{a}$ Df: degrees of freedom; SS: sum of squares; MS: Variance; $P$ : percent contribution. ${ }^{*}$ Pooled, Tabulated $F$-ratio at $99 \%$ confidence level: $F_{0.01,2,16}=6.23$.

Table 6. Analysis of Variance (ANOVA) for the heat affected zone (HAZ).

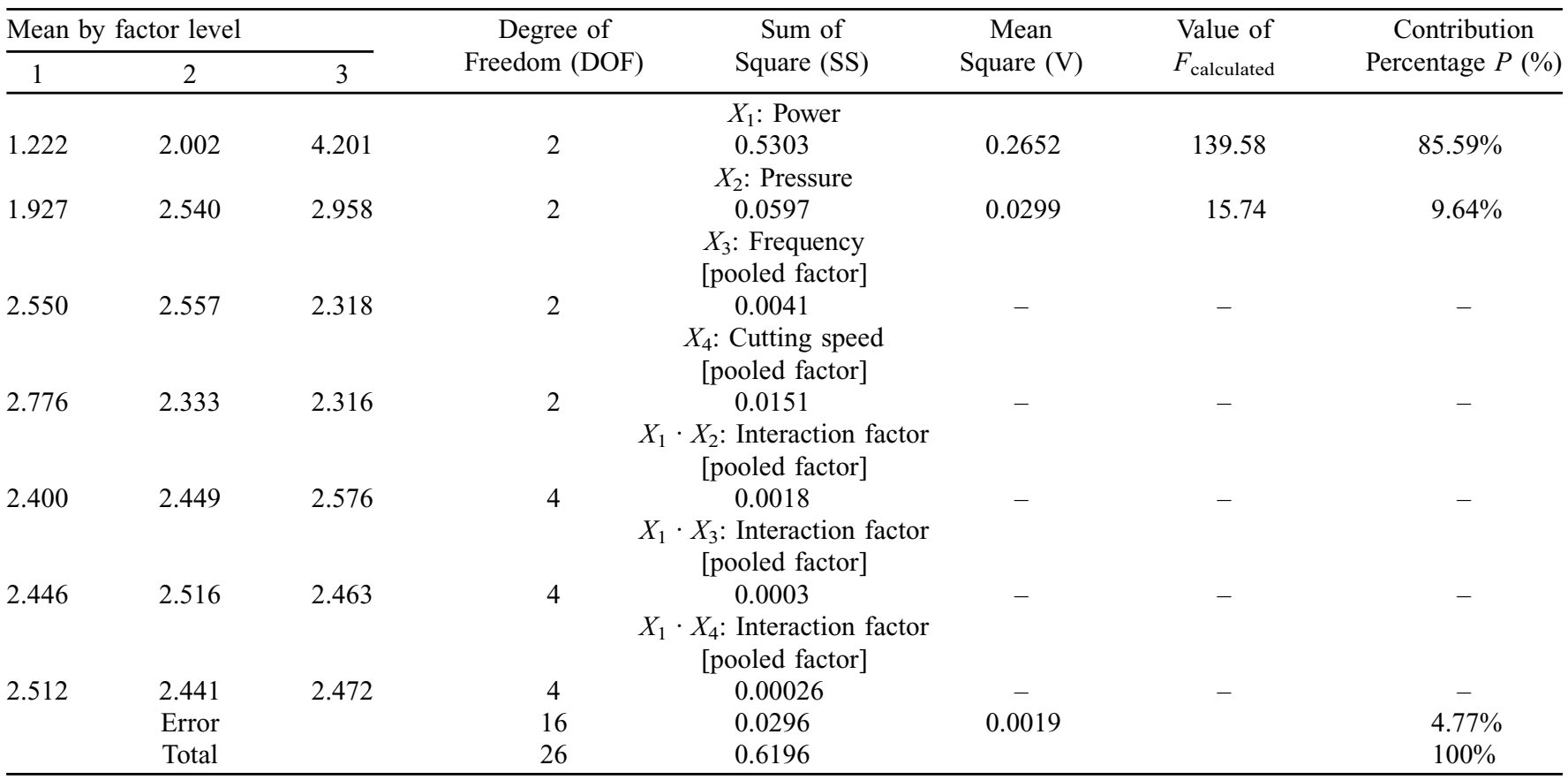

(alumina, slate, mils steel, stainless steel 37, polymers, composites, wood, high strength low alloy steel, aluminum copper, titanium, Kevlar, plastic, rubber, and aluminum composite), input process parameters (laser power, cutting speed, nozzle distance, gas pressure, gas type, focus position, laser cutting mode, laser pulse frequency, work piece thickness, duty cycle) 
Table 7. Effect of factors on $\mathrm{S} / \mathrm{N}\left(T_{\mathrm{a}}\right)^{\mathrm{a}}$.

\begin{tabular}{|c|c|c|c|c|}
\hline \multirow[t]{2}{*}{ Symbol } & \multirow[t]{2}{*}{ Factors } & \multicolumn{3}{|c|}{$\mathrm{S} / \mathrm{N}$ ratios $(\mathrm{dB})$} \\
\hline & & Level 1 & Level 2 & Level 3 \\
\hline$\overline{X_{1}}$ & Power & $2.452^{\mathrm{a}}$ & 41.588 & 96.945 \\
\hline$X_{2}$ & Pressure & $26.944^{\mathrm{a}}$ & 51.916 & 62.124 \\
\hline$X_{3}$ & Frequency & 53.842 & 43.697 & $43.445^{\mathrm{a}}$ \\
\hline$X_{4}$ & Cutting speed & 55.576 & 46.244 & $39.164^{\mathrm{a}}$ \\
\hline
\end{tabular}

${ }^{a}$ Optimum level.

and process responses (kerf taper and width, surface roughness, heat affected zone, striation formation and dross formation). As a new process with nontraditional nature, the objective is to design the laser cutting process for minimum outputs such as kerf width and taper, minimum surface roughness and minimum heat affected zone.

Rajpuohit and Patel [16] studied Laser cutting quality characteristics. Periodical lines (striations) are considered as noise affecting surface roughness and geometry precision of laser cut product. The mechanism leading to striations is not fully understood.

Phipon and Pradhan [20] used Genetic Algorithms to optimize laser beam machining operations. Minimum kerf taper and surface roughness are taken as process responses. Response surface methods are used to develop mathematical models relating responses to process parameters. Good prediction capabilities are obtained from this study. A Central Composite Design (CCD) of 31 points and 5 levels is employed for experimentation. This is a highly fractional array compared with $5^{4}=625$ experiments required by full factorial design. Chaki et al. [17] integrated a model of Artificial Neural Network (ANN) and Genetic Algorithm (GA) for prediction and optimization of quality characteristics of $\mathrm{Al}$ alloy during pulsed Nd:YAG laser cutting. The ANN serves the purpose of modeling and prediction of surface roughness and material removal rates. Other outputs can be added at any stage. The ANN model allows prediction within and outside process parameter ranges compared with any mathematical modeling techniques that allow prediction within parameter ranges. This study represents a good reference in relation to process single and multi objective optimization, modeling using ANN, past studies of the subject using Taguchi method, response surface methodology, and grey relational analysis.

\section{Taguchi methodology}

Genichi Taguchi developed a three stage methodology back in the 80 s $[14,15]$. The three stages are: systems design, parameter design and tolerance design. Figure 1 shows a procedure of Taguchi method $[14,15]$. In the present work, four control factors with three levels of each are considered. An $\mathrm{L}_{27} \mathrm{OA}$ is employed to plan experimentation due to reasonable number of experiments and interaction effects among variables. This means a total of $3^{4}=81$ experiments for a full factorial design is needed or 27 experiments for a fractional factorial design.

Kerf qualities such as kerf taper $\left(T_{\mathrm{a}}\right)$ and surface roughness $\left(R_{\mathrm{a}}\right)$ are optimized during pulsed Nd:YAG laser cutting of stainless steel sheet straight profile. Experiments are conducted under different cutting parameters, namely, power, oxygen pressure, pulse frequency and cutting speed. The combinations of cutting parameters are determined using $\mathrm{L}_{27} \mathrm{OA}$ as shown in Table 3. Analysis of Variance (ANOVA) is used to find the significant cutting parameters that affect mean response, variance of response and signal to noise ratios at different confidence levels respectively. The system design stage is crucial to later stages. In the parameter design stage, input process parameters and process responses are defined. Output responses are kerf width and kerf taper, surface roughness and heat affected zone. The experimental setup using the laser beam cutting machine is employed. Mapping between the laser beam machine and real experimental domain is done. The laser beam machine is calibrated to assure proper measurements of kerf taper and width and surface roughness. The heat affected zone is measured by a separate device. The parameter design stage involves:

- define the control variables and their practical domain in reality and in specific to the machine employed,

- define the \# of levels, each control variable can have,

- define an appropriate orthogonal array host this experiment.

A proper understanding of the limitations of these arrays is needed. Three replications at each setting of control variables are obtained. The three replications are used to obtain the mean, standard deviation and signal to noise ratio of response respectively.

\section{Experimentation}

The experiments are conducted on a $200 \mathrm{~W}$ pulsed $\mathrm{Nd}$ :YAG laser beam machining system with $\mathrm{CNC}$ work table (ROFIN DY x55-022 model) as shown in Figure 2. As an assist gas, oxygen is used and passed through a conical nozzle of $1.0 \mathrm{~mm}$ diameter co-axially with laser beam. The laser beam is focused using a lens with focal length of $50 \mathrm{~mm}$, and the minimum diameter of focused beam is about $0.47 \mathrm{~mm}$, stainless steel (316L) sheet with $3 \mathrm{~mm}$ thickness. Nozzle diameter, focal length of lens $200 \mathrm{~mm}$, nozzle standoff distance and sheet material thickness are kept constant throughout experimentation.

The performance characteristics $\left(T_{\mathrm{a}}\right.$ and $\left.R_{\mathrm{a}}\right)$ are affected by various input process parameters: power $\left(X_{1}\right)$, assist gas pressure $\left(X_{2}\right)$, pulse frequency $\left(X_{3}\right)$, and cutting speed $\left(X_{4}\right)$. The numerical values of these parameters are shown in Table 2 . A set of pilot experimentation is carried to decide the domain. A standard $\mathrm{L}_{27} \mathrm{OA}$ with interaction effects and experimental 


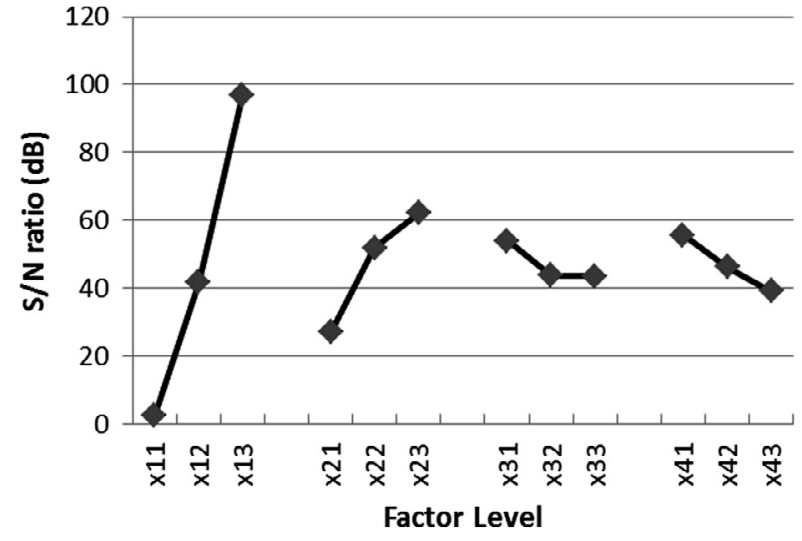

Figure 4. Effect of laser cutting parameters on $\mathrm{S} / \mathrm{N}$ ratios $\left(T_{\mathrm{a}}\right)$.

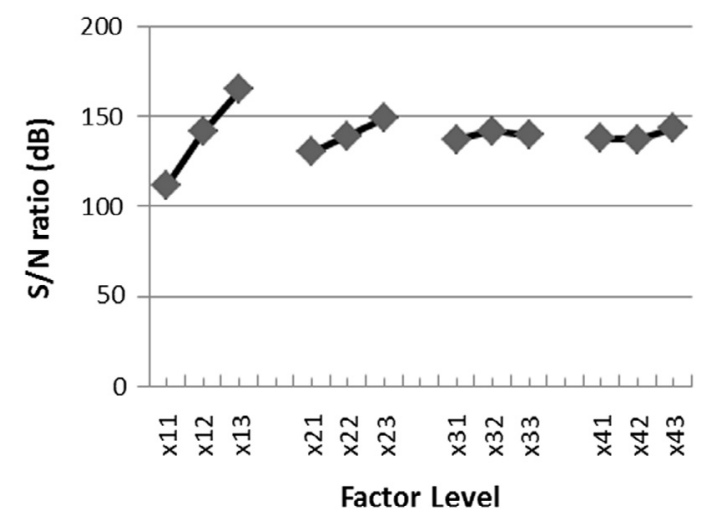

Figure 5. Effect of laser cutting parameters on $\mathrm{S} / \mathrm{N}$ ratios $\left(R_{\mathrm{a}}\right)$.

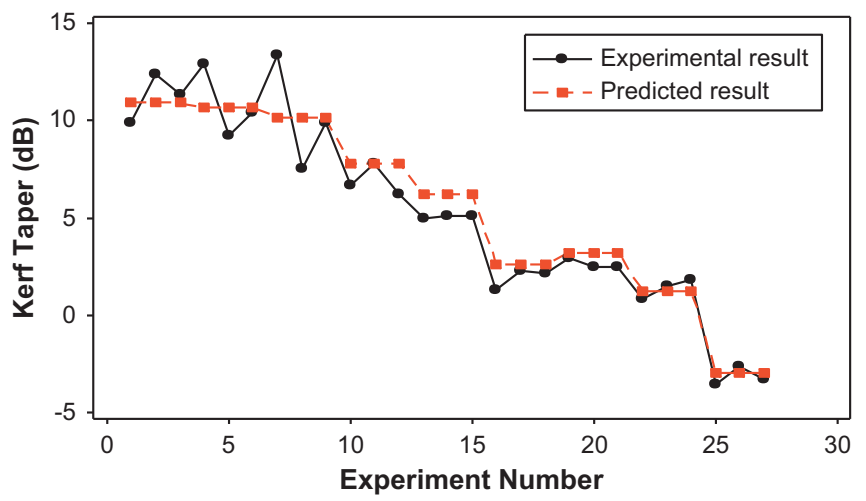

Figure 6. Comparison of experimental and predicted results for kerf taper.

responses are given in Appendix. Three replications for each experimental run are performed to obtain the $15 \mathrm{~mm}$ cut length (shown in Figure 3). The top and bottom kerf microscope (the tool-maker microscope) at $10 \times$ magnifications. $T_{\mathrm{a}}$ is computed using equation (1):

$$
T_{\mathrm{a}}=\frac{(\text { Top kerf width }- \text { Bottom kerf width })}{2 \pi \times \text { sheet thickness }}
$$

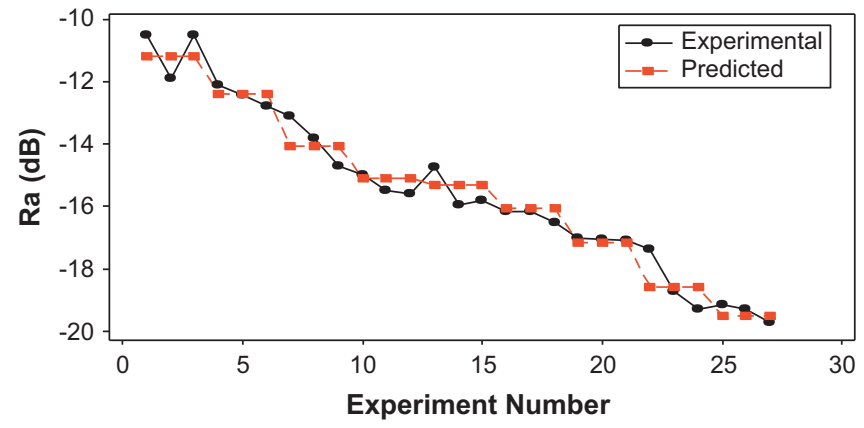

Figure 7. Comparison of experimental and predicted results for surface roughness.

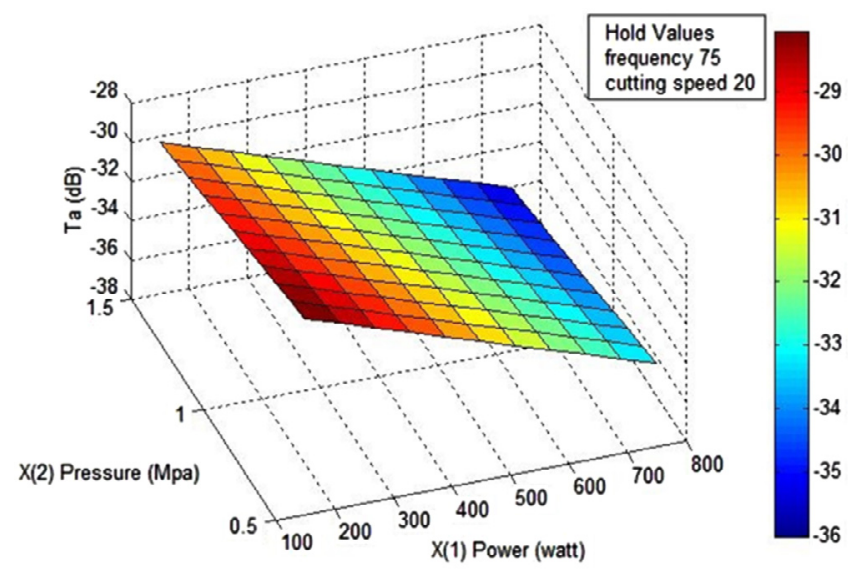

Figure 8. Response surface plot of $T_{\mathrm{a}}$ with power and oxygen pressure.

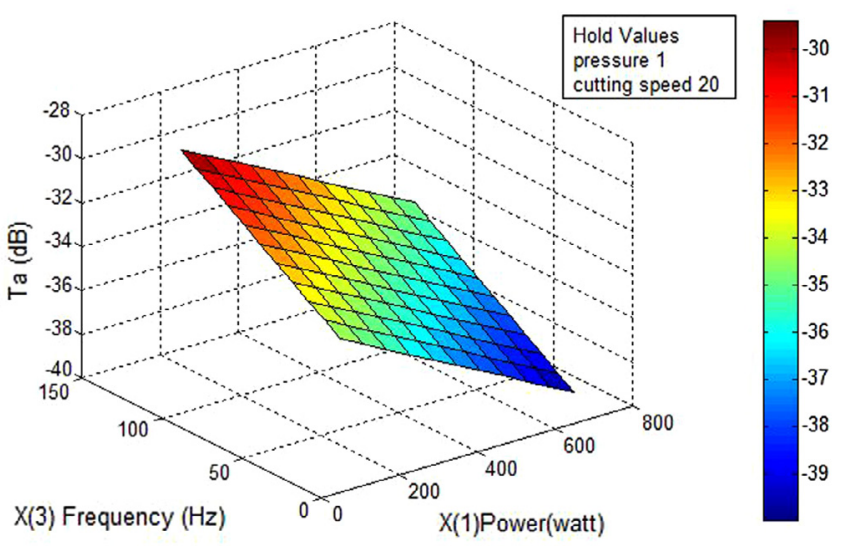

Figure 9. Response surface plot of $T_{\mathrm{a}}$ with power and frequency.

$R_{\mathrm{a}}$ value is measured using the Surface Roughness Tester (TAYLOR-HOBSON - SURTRONIC 3, 112/1500 - 1150483, DENMARK). All measurements are acquired using $4.00 \mathrm{~mm}$ evaluation length. Average values of $T_{\mathrm{a}}$ and $R_{\mathrm{a}}$ corresponding to each setting are also given in Appendix. 


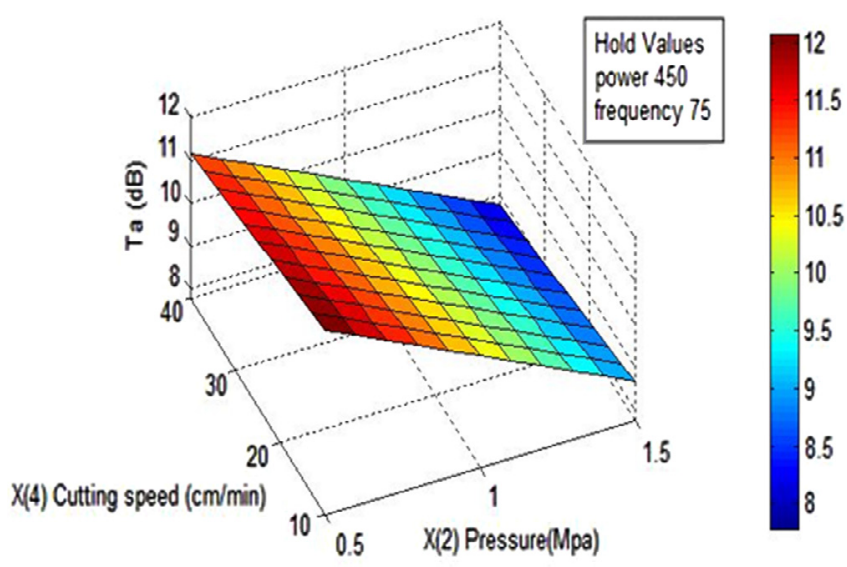

Figure 10. Response surface plot of $T_{\mathrm{a}}$ with power and cutting speed.

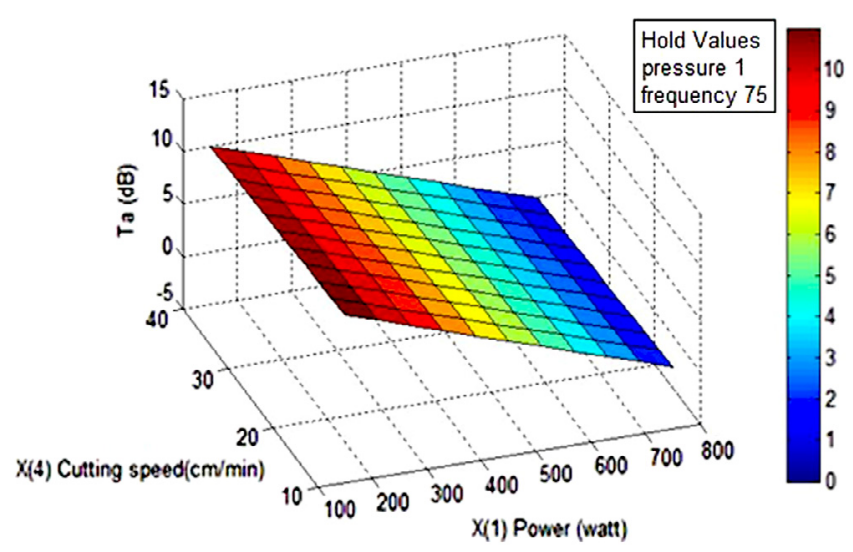

Figure 11. Response surface plot of $T_{\mathrm{a}}$ with pressure and cutting speed.

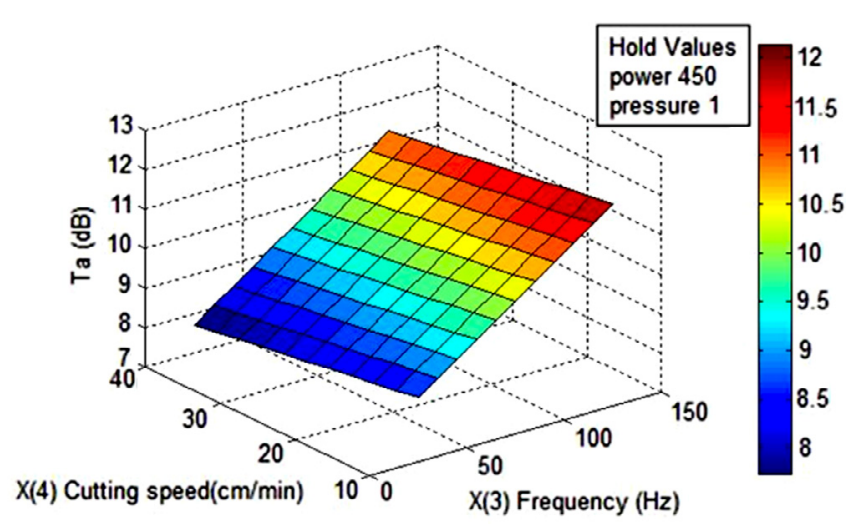

Figure 12. Response surface plot of $T_{\mathrm{a}}$ with frequency and cutting speed.

\section{Design of experiments and Taguchi method}

In this study, the Taguchi parameter design method is used to determine optimal machining parameters for minimization

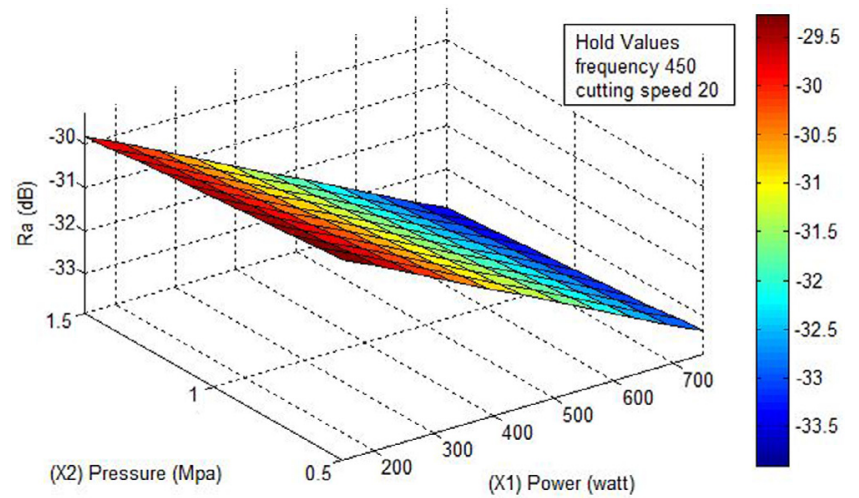

Figure 13. Response surface plot of $R_{\mathrm{a}}$ with power and oxygen pressure.

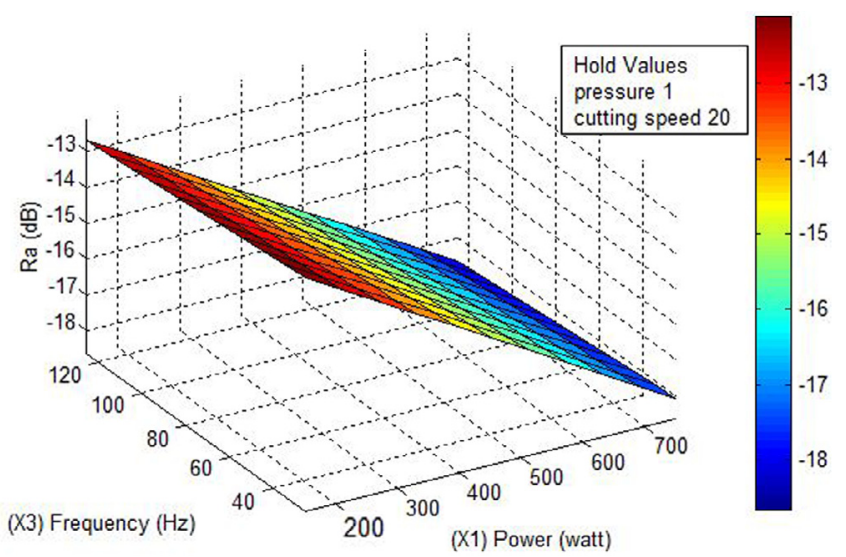

Figure 14. Response surface plot of $R_{\mathrm{a}}$ with power and pulse frequency.

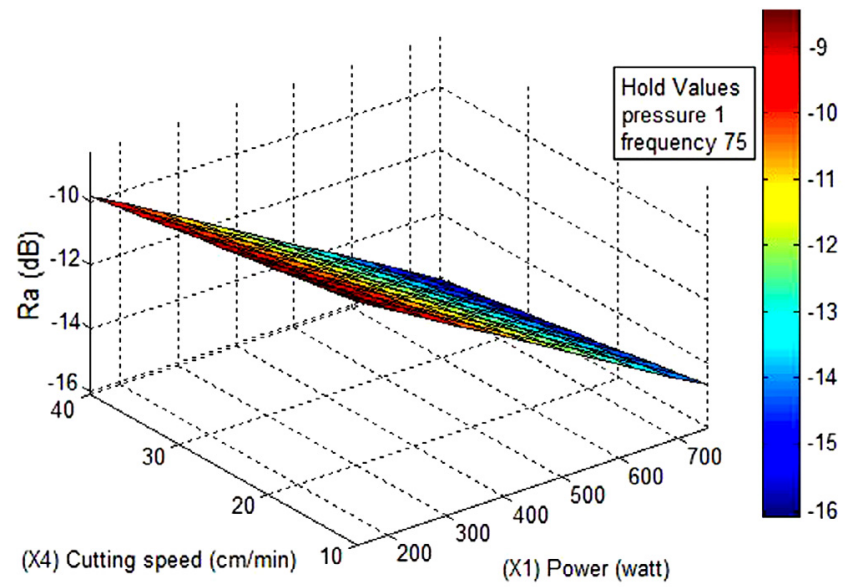

Figure 15. Response surface plot of $R_{\mathrm{a}}$ with power and cutting speed.

of $T_{\mathrm{a}}$ and $R_{\mathrm{a}}$. Four control factors: $X_{1}, X_{2}, X_{3}$ and $X_{4}$ and three interactions: $X_{1} \cdot X_{2}, X_{1} \cdot X_{3}$ and $X_{1} \cdot X_{4}$ are considered. The experimental observations are further transformed into lower 


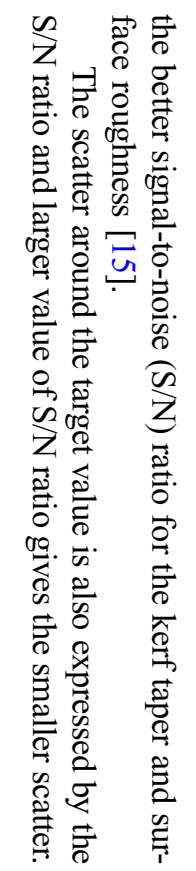
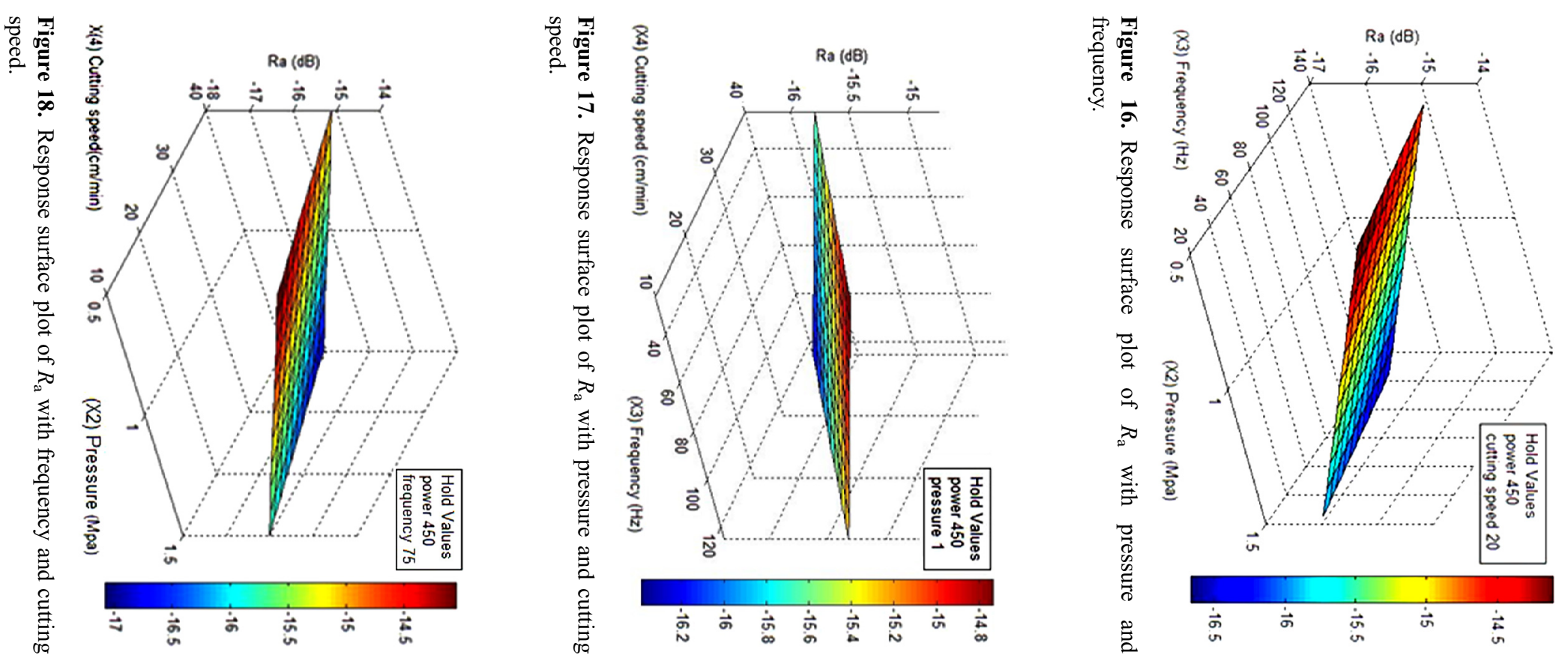

$\infty$

Table 8. Validation experiments and corresponding kerf taper, average surface roughness and heat affected zone.

\begin{tabular}{|c|c|c|c|c|c|c|c|c|c|c|c|c|c|c|c|c|}
\hline \multirow[t]{2}{*}{$\begin{array}{l}\text { Confirmation } \\
\text { experiment }\end{array}$} & \multirow[t]{2}{*}{ Power } & \multirow[t]{2}{*}{$\begin{array}{l}\text { Oxygen } \\
\text { pressure }\end{array}$} & \multirow[t]{2}{*}{ Frequency } & \multirow[t]{2}{*}{ Cutting speed } & \multicolumn{3}{|c|}{ Kerf taper (deg) } & \multirow[t]{2}{*}{ Mean } & \multicolumn{3}{|c|}{$\begin{array}{l}\text { Average surface roughness } \\
(\mu \mathrm{m})\end{array}$} & \multirow[t]{2}{*}{ Mean } & \multicolumn{3}{|c|}{ HAZ (mm) } & \multirow[t]{2}{*}{ Mean } \\
\hline & & & & & 1st trial & 2nd trial & 3rd trial & & 1st trial & 2nd trial & 3rd trial & & 1st trial & 2nd trial & 3rd trial & \\
\hline 1 & 150 & 1.5 & 75 & 25 & 0.431 & 0.387 & 0.430 & 0.416 & 5.341 & 4.466 & 4.476 & 4.761 & 0.174 & 0.190 & 0.185 & 0.183 \\
\hline 2 & 250 & 2.5 & 125 & 35 & 0.813 & 0.761 & 0.805 & 0.793 & 7.421 & 6.741 & 7.219 & 7.127 & 0.366 & 0.388 & 0.404 & 0.386 \\
\hline 3 & 350 & 2.75 & 175 & 15 & 0.965 & 1.131 & 1.279 & 1.125 & 7.976 & 8.540 & 9.374 & 8.630 & 0.513 & 0.449 & 0.591 & 0.518 \\
\hline 4 & 450 & 0.50 & 65 & 12 & 0.486 & 0.498 & 0.504 & 0.496 & 5.215 & 4.932 & 5.816 & 5.321 & 0.157 & 0.214 & 0.241 & 0.204 \\
\hline 5 & 550 & 0.25 & 190 & 18 & 0.402 & 0.362 & 0.307 & 0.357 & 6.543 & 7.126 & 5.609 & 6.426 & 0.195 & 0.174 & 0.198 & 0.189 \\
\hline 6 & 200 & 1 & 200 & 40 & 0.082 & 0.069 & 0.071 & 0.074 & 6.211 & 5.310 & 5.942 & 5.821 & 0.052 & 0.041 & 0.045 & 0.046 \\
\hline 7 & 600 & 3 & 50 & 10 & 1.813 & 1.671 & 1.664 & 1.716 & 9.784 & 9.831 & 9.980 & 9.865 & 0.589 & 0.564 & 0.605 & 0.586 \\
\hline 8 & 400 & 2 & 125 & 25 & 0.913 & 0.815 & 0.954 & 0.894 & 8.441 & 7.950 & 8.632 & 8.341 & 0.362 & 0.410 & 0.296 & 0.356 \\
\hline 9 & 200 & 3 & 200 & 10 & 0.986 & 1.102 & 0.984 & 1.024 & 9.210 & 8.124 & 7.122 & 8.152 & 0.511 & 0.530 & 0.501 & 0.514 \\
\hline 10 & 600 & 1 & 50 & 40 & 0.785 & 0.689 & 0.659 & 0.711 & 7.320 & 6.865 & 7.445 & 7.210 & 0.345 & 0.336 & 0.342 & 0.341 \\
\hline
\end{tabular}


Table 9. Mean, S/N and standard deviation of surface roughness using Taguchi method vs. RSM.

\begin{tabular}{|c|c|c|c|c|c|c|c|c|c|c|}
\hline \multirow[t]{2}{*}{$\begin{array}{l}\text { Confirmation } \\
\text { experiment }\end{array}$} & \multirow[t]{2}{*}{ Power } & \multirow[t]{2}{*}{$\begin{array}{l}\text { Oxygen } \\
\text { pressure }\end{array}$} & \multirow[t]{2}{*}{ Frequency } & \multirow[t]{2}{*}{$\begin{array}{l}\text { Cutting } \\
\text { speed }\end{array}$} & \multicolumn{3}{|c|}{$\begin{array}{c}\text { Average surface roughness }(\mu \mathrm{m}) \\
\text { Taguchi } \\
\end{array}$} & \multicolumn{3}{|c|}{$\begin{array}{c}\text { Average surface roughness }(\mu \mathrm{m}) \\
\text { RSM }\end{array}$} \\
\hline & & & & & Mean & $\mathrm{S} / \mathrm{N}$ & $\begin{array}{l}\text { Standard } \\
\text { deviation }\end{array}$ & Mean & $\mathrm{S} / \mathrm{N}$ & $\begin{array}{l}\text { Standard } \\
\text { deviation }\end{array}$ \\
\hline 1 & 150 & 1.5 & 75 & 25 & 4.761 & -13.586 & 0.50232 & 4.8900 & -13.1231 & 0.549294 \\
\hline 2 & 250 & 2.5 & 125 & 35 & 7.127 & -17.065 & 0.34921 & 7.3025 & -16.2945 & 0.034774 \\
\hline 3 & 350 & 2.75 & 175 & 15 & 8.63 & -18.739 & 0.70333 & 8.6031 & -17.6728 & -0.23048 \\
\hline 6 & 200 & 1 & 200 & 40 & 5.821 & -15.318 & 0.46253 & 5.7540 & -14.4701 & 1.069272 \\
\hline 7 & 600 & 3 & 50 & 10 & 9.865 & -19.882 & 0.10233 & 9.7486 & -21.2714 & -0.68546 \\
\hline 8 & 400 & 2 & 125 & 25 & 8.341 & -18.429 & 0.35183 & 7.5635 & -17.1677 & 0.257539 \\
\hline 9 & 200 & 3 & 200 & 10 & 8.152 & -18.273 & 1.04428 & 8.1701 & -15.5729 & -0.36771 \\
\hline 10 & 600 & 1 & 50 & 40 & 7.210 & -17.164 & 0.30524 & 7.3325 & -17.3566 & 0.751522 \\
\hline
\end{tabular}

Table 10. Kerf taper using Taguchi method vs. RSM for the validation experiments.

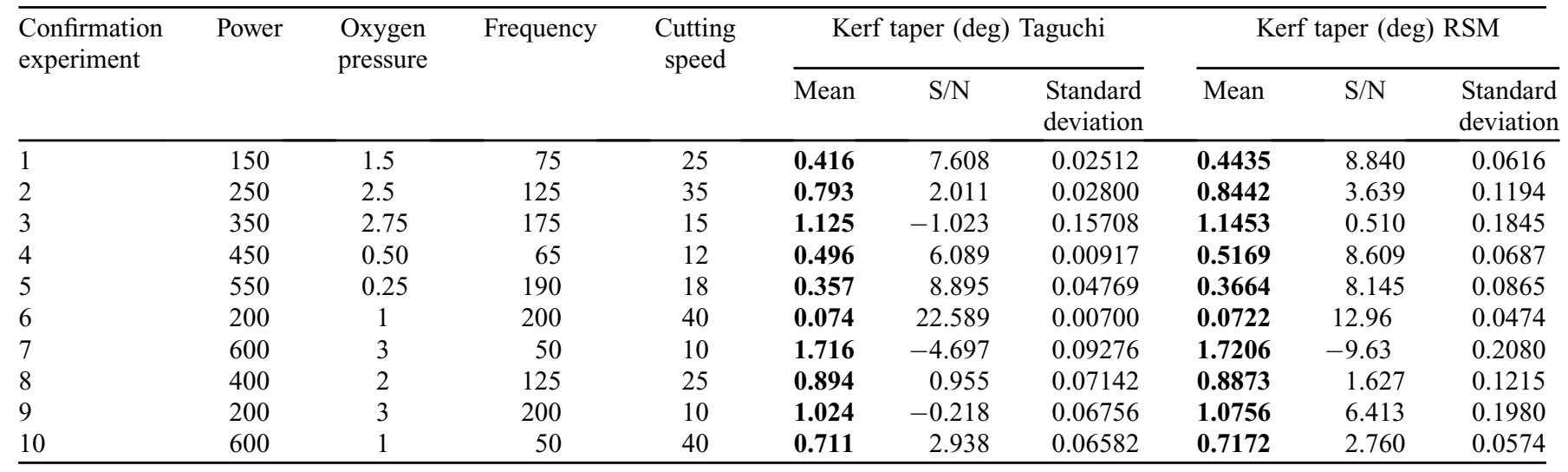

Table 11. Mean, $\mathrm{S} / \mathrm{N}$ and standard deviation of the HAZ using the Taguchi method vs. RSM.

\begin{tabular}{|c|c|c|c|c|c|c|c|c|c|c|}
\hline $\begin{array}{l}\text { Confirmation } \\
\text { experiment }\end{array}$ & Power & $\begin{array}{l}\text { Oxygen } \\
\text { pressure }\end{array}$ & Frequency & $\begin{array}{l}\text { Cutting } \\
\text { speed }\end{array}$ & \multicolumn{3}{|c|}{ HAZ (mm) Taguchi } & \multicolumn{3}{|c|}{ HAZ (mm) RSM } \\
\hline 2 & 250 & 2.5 & 125 & 35 & 0.386 & 8.261 & 0.019078 & 0.40280 & 9.968842 & -0.03850 \\
\hline 3 & 350 & 2.75 & 175 & 15 & 0.518 & 5.665 & 0.071116 & 0.50967 & 5.971949 & -0.04528 \\
\hline 4 & 450 & 0.50 & 65 & 12 & 0.204 & 13.681 & 0.042884 & 0.20643 & 14.30810 & 0.008152 \\
\hline 7 & 600 & 3 & 50 & 10 & 0.586 & 4.638 & 0.020664 & 0.59036 & 1.55622 & -0.02091 \\
\hline 8 & 400 & 2 & 125 & 25 & 0.356 & 8.897 & 0.057236 & 0.35407 & 9.13435 & -0.02284 \\
\hline 9 & 200 & 3 & 200 & 10 & 0.514 & 4.589 & 0.014731 & 0.52347 & 7.03958 & -0.05338 \\
\hline 10 & 600 & 1 & 50 & 40 & 0.341 & 9.344 & 0.004583 & 0.31290 & 10.31207 & 0.040256 \\
\hline
\end{tabular}

Depending upon the objectives of the experiment, there may be other quality characteristics. Lower kerf taper and surface roughness are desirable. The Mean Square Deviation (MSD) of kerf taper and surface roughness from the target value for LB type characteristics can be expressed as [11]:

$$
\operatorname{MSD}=-10 \log (1 / n)\left(\sum y_{i}^{2}\right)
$$

Where $y_{i}$ are the observed data (or quality characteristics) of the $i^{\text {th }}$ trial and $n$ is the number of replications. Similar work is cited by El-Taweel et al. on Kevlar 49 composite materials using $\mathrm{CO}_{2}$ Laser [19].

\section{Response surface methodology (RSM)}

Response surface methodology is a mathematical and statistical based tools used to model and analyze multi-variable systems [25]. The general form between independent and dependent variables is unknown. Accordingly, RSM is employed to approximate response function in terms of 
Table 12. Experimental vs. predicted results.

\begin{tabular}{|c|c|c|c|c|c|c|c|c|c|c|}
\hline & \multirow[t]{2}{*}{ Run no. } & \multicolumn{3}{|c|}{ Experimental result } & \multicolumn{3}{|c|}{ Predicted result } & \multicolumn{3}{|c|}{ Prediction error $\%$} \\
\hline & & $T_{\mathrm{a}}$ & $R_{\mathrm{a}}$ & HAZ & $T_{\mathrm{a}}$ & $R_{\mathrm{a}}$ & HAZ & $T_{\mathrm{a}}$ & $R_{\mathrm{a}}$ & HAZ \\
\hline \multirow[t]{5}{*}{ Part A } & 1 & 0.416 & 4.761 & 0.183 & 0.4435 & 4.8900 & 0.19040 & 6.61 & 3.82 & 4.04 \\
\hline & 2 & 0.793 & 7.127 & 0.386 & 0.8442 & 7.3025 & 0.40280 & 6.43 & 2.46 & 4.35 \\
\hline & 3 & 1.125 & 8.63 & 0.518 & 1.1453 & 8.6031 & 0.50967 & 1.80 & 0.31 & 1.61 \\
\hline & 4 & 0.496 & 5.321 & 0.204 & 0.5169 & 5.3934 & 0.20643 & 4.21 & 1.36 & 1.19 \\
\hline & 5 & 0.357 & 6.426 & 0.189 & 0.3664 & 6.7472 & 0.19484 & 2.63 & 4.99 & 3.09 \\
\hline \multirow{5}{*}{ Part B } & 7 & 1.716 & 9.865 & 0.586 & 1.7206 & 9.7486 & 0.59036 & 0.27 & 1.18 & 0.74 \\
\hline & 8 & 0.894 & 8.341 & 0.356 & 0.8873 & 7.5635 & 0.35407 & 0.67 & 9.32 & 0.54 \\
\hline & 9 & 1.024 & 8.152 & 0.514 & 1.0756 & 8.1701 & 0.52347 & 5.04 & 0.22 & 1.84 \\
\hline & 10 & 0.711 & 7.210 & 0.341 & 0.7172 & 7.3325 & 0.31290 & 0.87 & 1.70 & 8.24 \\
\hline & \multicolumn{7}{|c|}{ Average percentage of error } & 1.86 & 2.71 & 2.93 \\
\hline
\end{tabular}

predictor variables. The relationship between the cutting forces and process parameters is generally nonlinear. The $2^{\text {nd }}$ order polynomial response surface mathematical model can be expressed as:

$$
y=F\left(X_{1}, X_{2}, X_{3}, X_{n}\right)+\varepsilon
$$

Where $y$ is the response, $X_{i}(i=1,2,3, \ldots n)$ are process variables, and $\varepsilon$ is the error term. The function $F$ is normally a polynomial function of second, third, fourth order (or even higher) with cross and mixed terms. Employing a quadratic polynomial, $y$ is written as:

$$
y=\beta_{o}+\sum_{i=1}^{n} \beta_{i} X_{i}+\sum_{i \prec j}^{n} \sum \beta_{i j} X_{i} X_{j}+\sum_{i=1}^{n} \beta_{i i} X_{i}^{2}+\varepsilon
$$

Where $\beta_{o}$ represents unknown polynomial coefficients. These unknown coefficients $\beta_{i}(i=0,1,2, \ldots n)$ are estimated by the ordinary Least Squares method. The model is written in matrix form as:

$$
Y=X \beta+\varepsilon
$$

Where:

$$
\begin{aligned}
& Y=\left\{\begin{array}{l}
y_{1} \\
y_{2} \\
y_{3} \\
y_{4} \\
y_{n}
\end{array}\right\}, \quad X=\left[\begin{array}{llllll}
1 & X_{11} & X_{12} & X_{13} & \ldots & X_{1 k} \\
1 & X_{21} & X_{22} & X_{23} & \ldots & X_{2 k} \\
& & & & & \\
& & & & & X_{n h}
\end{array}\right] \text {, } \\
& \beta=\left\{\begin{array}{l}
\beta_{1} \\
\beta_{2} \\
\beta_{3} \\
\beta_{n}
\end{array}\right\}, \quad \varepsilon=\left\{\begin{array}{l}
\varepsilon_{1} \\
\varepsilon_{2} \\
\varepsilon_{3} \\
\\
\varepsilon_{n}
\end{array}\right\}
\end{aligned}
$$

These parameters can be written in matrix form as:

$$
\beta=\left(X^{T} X\right)^{-1} X^{T} Y
$$

Where $X$ is the matrix of factors level and $Y$ is the force responses. A certain domain may be in need for several RSM model polynomials to model adequately. The evaluation and presence of curvatures are dealt with by using 3-level orthogonal arrays respectively. Analysis of variance is used to formally test for significance of main and interaction effects. A common approach consists of removing any non-significant term from the full model. Analysis of variance was performed initially to screen out non significant variables. Several decision rules are employed to judge whether a term should be included or excluded from the full model. Other attempts deal with multiresponse problems using the desirability function. In our opinion, this is not an objective index and hence, the resulting optimum has to be interpreted with care. Multi-variate responses may have several difficulties resulting from dependencies among error estimations, error among expected value of responses and linear dependencies in the original data [25].

Adequacy of models is checked by several tools such as residual analysis, normal probability plots, model form modifications, etc. Several approximations are developed for the response surfaces and verified further by additional experiments.

\section{Results and analysis}

Analysis of Variance (ANOVA) is a statistical technique for quantitative estimation of relative contribution of each control factor on overall measured response. The relative significance of factors is often represented in terms of $F$-ratio or percentage contribution [13]. The $F$-ratio indicates more significance of the factor. In the present work, ANOVA is employed for analyzing significance of $X_{1}, X_{2}, X_{3}$ and $X_{4}$ on combined kerf quality parameter and surface roughness given in Tables 4 and 5. An estimate of the sum of squares for the pooled error can be obtained by pooling the sum of squares of factors with the lowest sum of squares of $X_{3}, X_{4}$ and all relevant interactions. The pooled error has 16 degrees of freedom and a sum of squares of 53.516. Hence, the pooled mean square error is 3.3447. The $F$-value is the ratio of the mean square factor to the variance of pooled error. $X_{1}$ and $X_{2}$ are significant parameters affecting the kerf taper quality at $99 \%$ confidence level. 
On the other hand, an estimate of the sum of squares for the pooled error can be obtained by pooling the sum of squares of factors with the lowest sum of squares of $X_{3}, X_{4}$ and all relevant interactions. The pooled error has 16 degrees of freedom and a sum of squares of 28.688. Hence, the pooled mean square error is $0.6013 . X_{1}$ and $X_{2}$ are significant parameters affecting the surface roughness at $99 \%$ confidence level.

The results of the ANOVA with the kerf taper and surface roughness are shown in Tables 4 and 5, respectively. This analysis was carried out for a significance level of $\alpha=0.01$, i.e. for a confidence level of $99 \%$. Tables 5 and 6 show the $P$-values, that is, the realized significance levels, associated with the $F$-tests for each source of variation. The sources with a $P$-value less than 0.01 are considered to have a statistically significant contribution to the performance measures.

Table 4 shows that the only significant factor for the power is $X_{1}$, which explains $79.86 \%$ of the total variation. The next largest contribution comes from pressure with $11.61 \%$, which does not have statistical significance. The frequency and cutting speed the interactions have much lower levels of contribution.

Multiple quality characteristic $\left(R_{\mathrm{a}}\right)$ is shown in Table 5 shows that the only significant factor for the power is $X_{1}$, which explains $84.53 \%$ of the total variation and the next largest contribution comes from pressure with $10.28 \%$. This does not have statistical significance. The frequency and cutting speed the interactions have much lower levels of contribution. Similar results are given in Table 6 for the Heat Affected Zone (HAZ). The effect of different operating parameters on $S / N$ ratio comprising the kerf taper is shown in Table 7 and Figure 4. It is clear that, optimum levels of different control factors for obtaining minimum kerf taper is: cutting speed at level 1 $(150 \mathrm{~W})$, pressure at level $1(0.5 \mathrm{MPa})$, pulse frequency at level $3(125 \mathrm{~Hz})$ and cutting speed at level $3(40 \mathrm{~cm} / \mathrm{min})$.

Optimum levels of different control factors for obtaining minimum kerf taper is: cutting speed at level $1(150 \mathrm{~W})$, pressure at level $1(0.5 \mathrm{MPa})$, pulse frequency at level $3(125 \mathrm{~Hz})$ and cutting speed at level $3(40 \mathrm{~cm} / \mathrm{min})$. Relative contribution of the controlling parameters on kerf quality is shown in Table 7.

The effect of different operating parameters on $\mathrm{S} / \mathrm{N}$ ratio comprising the surface roughness is shown in Figure 5.

Summary of control factors effects ( $\mathrm{S} / \mathrm{N}$ ratio values) are gives in Appendix.

\section{RSM for the kerf taper $\left(T_{\mathrm{a}}\right)$ and the average surface roughness $\left(R_{\mathrm{a}}\right)$}

A statistical regression analysis is performed to analyze the laser cutting of stainless steel (316L) as function of power, pressure, frequency and cutting speed. The models are developed using Matlab software for the kerf taper, surface roughness and the heat affected zone respectively. These models will be used further for validation purposes vs. real experiments. Once validated, the models will be optimized for the best process setting that results in minimum kerf taper, surface roughness and heat affected zone. Mathematical model based on $\mathrm{S} / \mathrm{N}$ ratio developed for minimum kerf taper is as follows:

$$
\begin{aligned}
T_{\mathrm{a}}= & 12.3339-0.002 X_{1}-2.2722 X_{2}+0.0499 X_{3} \\
& -0.0304 X_{4}-0.0073 X_{1} X_{2}-0.0001 X_{1} X_{3}
\end{aligned}
$$

Kerf taper based on standard deviation:

$$
\begin{aligned}
T_{\mathrm{a}}= & 0.0132+0.0001 X_{1}+0.0280 X_{2}+0.0002 X_{3} \\
& -0.0015 X_{4}+0.0062\left(X_{2}\right)^{2}
\end{aligned}
$$

Kerf taper based on mean values:

$$
\begin{aligned}
T_{\mathrm{a}}= & -0.057+0.0012 X_{1}+0.3657 X_{2}-0.0011 X_{3} \\
& -0.00664 X_{4}+0.0091\left(X_{2}\right)^{2}
\end{aligned}
$$

Similarly, the mathematical model developed for surface roughness based on $\mathrm{S} / \mathrm{N}$ ratio is:

$$
\begin{aligned}
R_{\mathrm{a}}= & -8.98366-0.0073 X_{1}-0.54769 X_{2}-0.00593 X_{3} \\
& -0.04662 X_{4}-0.00314 X_{1} X_{2}+0.000025 X_{1} X_{4}
\end{aligned}
$$

Average surface roughness based on standard deviation:

$$
\begin{aligned}
R_{\mathrm{a}}= & 0.908422-0.00026 X_{1}-0.16631 X_{2}-0.0006 X_{3} \\
& +0.007159 X_{4}-0.1112\left(X_{2}\right)^{2}+0.0000081\left(X_{3}\right)^{2}
\end{aligned}
$$

Average surface roughness based on mean:

$$
\begin{aligned}
R_{\mathrm{a}}= & 1.459249+0.006813 X_{1}+1.44 X_{2}-0.00138 X_{3} \\
& +0.007159 X_{4}-0.0239\left(X_{2}\right)^{2}+0.0000361\left(X_{3}\right)^{2} \\
& +0.0000386\left(X_{4}\right)^{2}
\end{aligned}
$$

\section{Validation of models}

Validation of the mathematical models with the experimental results is shown in Figure 6. The percentage of prediction error is calculated as:

$$
\begin{aligned}
\text { Prediction error } \%= & \frac{\text { Experimental result }- \text { Predicted result }}{\text { Experimental result }} \\
& \times 100
\end{aligned}
$$

The average percentage deviation in the kerf taper and surface roughness based on $\mathrm{S} / \mathrm{N}$ ratio values are $21.14 \%$ and $2.86 \%$ respectively. Table 7 indicates that the average percentage accuracy in the kerf taper and surface roughness based on $\mathrm{S} / \mathrm{N}$ ratio values are $78.86 \%$ and $97.14 \%$ respectively.

Figures 6 and 7 give the measured vs. predicted kerf taper based on $\mathrm{S} / \mathrm{N}$ ratio and surface roughness.

Response surface plots of kerf taper as function of different process variables are given in Figures 8-12. Similarly, response surface plots of surface roughness are given in Figures 13-18 respectively. 
Due to the pulsed nature of Nd:YAG laser cutting process, it is very difficult to obtain high surface quality. Therefore, the relative effects of laser cutting parameters such as power, oxygen pressure, pulse frequency, and cutting speed on $R_{\mathrm{a}}$ during laser cutting of stainless steel $(316 \mathrm{~L})$ is needed. The combined effects of power and oxygen pressure on $R_{\mathrm{a}}$ are shown in Figure 13. Pulse frequency and cutting speed are taken as constant values of $75 \mathrm{~Hz}$ and $20 \mathrm{~cm} / \mathrm{min}$, respectively. The surface plot reflects that power has linear effect on $R_{\mathrm{a}}$ at different assisted oxygen pressure.

At high level of power, variation in $R_{\mathrm{a}}$ value is large but at lower level of power, variation in $R_{\mathrm{a}}$ is relatively less with respect to the oxygen pressure. Oxygen pressure and cutting speed are taken as constant at $(1 \mathrm{MPa})$ and $(20 \mathrm{~cm} / \mathrm{min})$ in Figure 14.

Figures 15 and 16 show the effect of power, cutting speed and pressure, frequency respectively on $R_{\mathrm{a}}$ keeping pressure, pulse frequency and power and cutting speed respectively as a constant value. It is also observed that power, pressure at low level the surface roughness is relatively less with respect to cutting speed and frequency respectively.

Figure 17 shows the effects of pressure and cutting speed on $R_{\mathrm{a}}$ keeping the power and pulse frequency as constant (at middle value). It is observed that the nature of variation of $R_{\mathrm{a}}$ with applied pressure for the different cutting speeds is same as shown earlier in Figure 18 with applied pulse frequency. Here, $R_{\mathrm{a}}$ first decreases and then increases following a curved shape with the increase in pressure and pulse frequency. However, $R_{\mathrm{a}}$ decreases with the decrease in cutting speed.

\section{Verification experiments}

Table 8 gives the settings of the confirmation experiments for the laser cutting process. The five settings are taken at the lower and maximum limits of the power, oxygen pressure, frequency and cutting speed. Three replications are taken for the kerf taper (degree), average surface roughness $(\mu \mathrm{m})$ and heat affected zone $(\mathrm{mm})$. The mean, standard deviation and signal-to-noise ratios are calculated and compared later to prediction models.

Table 9 gives a comparison between the surface roughness measurements $(\mu \mathrm{m})$ using Taguchi and RSM approaches. This comparison is gives in terms of the mean, standard deviation and signal-to-noise ratios. Using the mean as a measure, the models developed earlier deviate from actual measurements from $-4.99 \%$ to $+9.32 \%$. Using the standard deviation as a measure, the models developed deviate from actual measurements from $-146 \%$ to $+769.8 \%$. Using the $\mathrm{S} / \mathrm{N}$ ratio as a measure, the models developed deviate from actual measurements from $1.12 \%$ to $14.776 \%$. Accordingly, it is recommended to use the developed models to predict the average and signal to noise ratio of surface roughness.

Table 10 gives confirmation and prediction results for the kerf taper in degree. Using the mean as a measure, the developed earlier deviate from the actual measurements from $-6.450 \%$ to $+2.43 \%$. Using the signal to noise ratios as a measure, the models deviate from the actual measurements from $-105 \%$ to $+149 \%$. Using the standard deviations as a measure, the models deviate from the actual measurements from $-649 \%$ to $+12.79 \%$. According, it is recommended to use developed models to predict mean kerf taper in degree.

Table 11 gives confirmation and prediction results for the heat affected zone. Using the mean as a measure, the different between the developed and predicted models vary from $-4.35 \%$ to $+8.24 \%$. Using the standard deviation as a measure, the different between the developed and predicted models vary from $-778 \%$ to $+462 \%$. Using the $\mathrm{S} / \mathrm{N}$ ratio as a measure, the different between the developed and predicted models vary from $-53.4 \%$ to $66.4 \%$. Accordingly, it is recommended to use the developed models to predict the average HAZ.

\section{Critique of methodology}

Several critiques can be mentioned for the experimental design chosen.

1. $\mathrm{L}_{27} \mathrm{OA}$ is used to host 4-3 level variables. This results in 81 experiments and $\mathrm{L}_{27} \mathrm{OA}$ is simple a $1 / 3$ the number of experiments chosen. The 4-3 level variables result in six interaction effects; these are $X_{1} \cdot X_{2}, X_{1} \cdot X_{3}, X_{1} \cdot X_{4}$, $X_{2} \cdot X_{3}, X_{2} \cdot X_{4}, X_{3} \cdot X_{4}$. Only four interactions due to search graph limitation are considered.

2. The approach taken allows minimization of kerf taper, surface roughness and heat affected zones one at a time due to the usual limitations of design of experiments in dealing with several responses. There is a need for multi objective optimization formulation of laser cutting operations.

3. Other sources of noise for laser cutting operations need to be identified, modeled and optimized.

4. A modified model can be developed by adding $\mathrm{L}_{27} \mathrm{OA}$ and the 10 experiments. This will result in 37 experiments. The revised model will be more adequate model.

\section{Conclusions}

The kerf taper and average surface roughness are optimized simultaneously during pulsed Nd:YAG laser cutting of stainless steel (316L) sheet. The following conclusions are drawn:

1. Results of Taguchi optimization indicates that best kerf quality are power at low level $150 \mathrm{~W}$, gas pressure at $0.5 \mathrm{MPa}$, pulse frequency at high level $125 \mathrm{~Hz}$ and cutting speed at $40 \mathrm{~cm} / \mathrm{min}$. At the same average surface roughness are power at low level $150 \mathrm{~W}$, gas pressure at $0.5 \mathrm{MPa}$, pulse frequency at low level $25 \mathrm{~Hz}$ and cutting speed at $20 \mathrm{~cm} / \mathrm{min}$.

2. Power and Assist gas pressure significantly affect the kerf quality in the operating range of process parameters.

3. Ta is found to be significantly affected by power, oxygen pressure, pulse frequency, cutting speed and interaction effect of oxygen pressure and frequency. On the other 
hand, $R_{\mathrm{a}}$ is found to be significantly affected by power, oxygen pressure, pulse frequency, cutting speed, interaction effect of oxygen pressure and cutting speed.

4. Validation of RSM models indicates average percentage deviation in the kerf taper and surface roughness based on $\mathrm{S} / \mathrm{N}$ ratio values are $21.14 \%$, and $2.86 \%$ respectively.

5. From the response surface plot, it is observed that the pulse frequency and cutting speed have less effects on $T_{\mathrm{a}}$ compared to other parameters. But lower value of $R_{\mathrm{a}}$ can be obtained at lower level of process parameters except cutting speed in the present study.

6. Utilize search graph techniques to assign $X_{1}, X_{2}, X_{3}$, and $X_{4}$ and respective interactions $X_{1} \cdot X_{2}, X_{1} \cdot X_{3}, X_{1} \cdot X_{4}$, $X_{2} \cdot X_{3}, X_{2} \cdot X_{4}$, and $X_{3} \cdot X_{4}$ [15]. Interactions may become important if looked at thoroughly although others have ignored their effects [19].

7. Ten confirmation experiments are carried to verity models developed previously. The models developed show good prediction capabilities for the kerf width, surface roughness and heat affected zone as given in Table 12.

Acknowledgements. Special appreciation are due to CMRDI, Helwan, Egypt for allowing to carry all required experimentation and validation of models.

\section{References}

1. A.K. Dubey, V. Yadava, Robust parameter design and multiobjective optimization of laser beam cutting for cutting for aluminium alloy sheet, Int. J. Adv. Manuf. Technol. 38 (2008) 268-277.

2. C. Brecher, M. Emonts, C.-J. Rosen, J.-P. Hermani, Laser assisted milling of advanced materials, Phys. Procedia 12 (2011) 599-606.

3. D. Schuocker, Laser cutting, Mater. Manuf. Process. 4 (2007), 311-330.

4. K.A. Ghany, M. Newishy, Cutting of $1.2 \mathrm{~mm}$ thick austenitic stainless steel sheet using pulsed and $\mathrm{CW}$ Nd:YAG laser, J. Mater. Process. Technol. 168 (2005) 438-447.

5. G. Chryssolouris, Laser machining - theory and practice (mechanical engineering series), Springer-Verlag, New York, 1991.

6. A.K. Dubey, V. Yadava, Laser beam machining - a review, Int. J. Mach. Tools Manuf. 48 (2008) 609-628.

7. G. Thawari, J.K. Sarin Sundar, G. Sundararajan, S.V. Joshi, Influence of process parameters during pulsed Nd:YAG laser cutting of nickel-base superalloys, J. Mater. Process. Technol. 170 (2005) 222-239.

8. http://www.aisi-stainless.com/Selling-list/316L-StainlessSteel-supplier-316L-stainless-steel-Applications.html
9. A. Sharma, V. Yadava, R. Rao, Optimization of kerf quality characteristics during Nd:YAG laser cutting of nickel based superalloy sheet for straight and curved cut profiles, Opt. Lasers Eng. 48 (2010) 915-925.

10. M. Boutinguiza, J. Pou, F. Lusquinos, F. Quintero, R. Soto, M. Perez-Amor, K. Watkins, W.M. Steen, $\mathrm{CO}_{2}$ laser aluminum alloy sheet, Int. J. Adv. Manuf. Technol. 38 (2008) 268-277.

11. C. Karatas, O. Keles, I. Uslan, Y. Usta, Laser cutting of steel sheets: influence of workpiece thickness and beam waist position on kerf size and stria formation, J. Mater. Process. Technol. 172 (2006) 22-29.

12. C.H. Li, M.J. Tsai, C.D. Yang, Study of optimal laser parameters for cutting QFN packages by Taguchi's matrix method, Opt. Laser Technol. 39 (2007) 786-795.

13. N. Tosun, L. Ozler, Optimization for hot turning operations with multiple performance characteristics, Int. J. Adv. Manuf. Technol. 23 (2004) 777-782.

14. M.S. Phadke, Quality engineering using robust design, Prentice Hall, New Jersey, 1989.

15. P.J. Ross, Taguchi techniques for quality engineering, McGraw-Hill, New Delhi, 1988.

16. S.R. Rajpurohit, D.M. Patel, Striation mechanism in laser cutting - the review, International J. Engineering Research and Applications (IJERA) 2 (2012) 457-461

17. S. Chaki, R.N. Bathe, S. Ghosal, G. Padmanabham, Multi objective optimization of pulse Nd:YAG laser cutting process using integrated ANN-NSGAII model, J. Intell. Manuf. (2015), DOI: $10.1007 / \mathrm{s} 10845-015-1100-2$.

18. A. Sharma, V. Yadava, Optimization of kerf quality using robust design of experiments during Nd:YAG laser cutting of thin $\mathrm{Al}$ alloy sheet for straight profile, Int. J. Mech. Eng. 1 (2011) 1-8.

19. T.A. El-Taweel, A.M. Abdel-Maaboud, B.S. Azzam, A.E. Mohammad, Parametric studies on the $\mathrm{CO} 2$ laser cutting of Kevlar-49 composite, Int. J. Adv. Manuf. Technol. 40 (2009) 907-917.

20. R. Phipon, B.B. Pradhan, Control parameters optimization of laser beam machining using GA, Int. J. Comput. Eng. Res. 2 (2012) 1510-1516.

21. R. Miroslav, M. Milos, Experimental investigations of $\mathrm{CO} 2$ laser cut quality: a review, Nonconventional Technologies Review 4 (2011) 35-42.

22. R. Miroslav, D. Predrag, Research on surface roughness by laser cut, The Annals of University of Galati XII (2006) 41-88.

23. K. Huehnlein, K. Tschirpke, R. Hellmann, Optimization of Laser Cutting Processes Using Design of Experiments, Physics Procedia 5 (2010) 243-252.

24. B. Adelmann, R. Hellmann, Fast Laser Cutting Optimization Algorithm, Physics Procedia 12 (2011) 591-598.

25. A.P. Paiva, J.R. Ferreira, P.P. Balestrassi, A multivariate hybrid approach applied to AISI 52100 hardened steel turning optimization, Journal of Materials Processing Technology 189 (2007) 26-35.

Cite this article as: Gadallah MH \& Abdu HM: Modeling and optimization of laser cutting operations. Manufacturing Rev. 2015, 2, 20. 


\section{Appendix}

Experimental observations using $\mathrm{L}_{27} \mathrm{OA}$.

\begin{tabular}{|c|c|c|c|c|c|c|}
\hline \multirow[t]{2}{*}{ Expt. no. } & \multicolumn{3}{|c|}{$T_{\mathrm{a}}(\mathrm{deg}$.) (with three replications) } & \multicolumn{3}{|c|}{$R_{\mathrm{a}}(\mu \mathrm{m})$ (with three replications) } \\
\hline & $y_{1}$ & $y_{2}$ & $y_{3}$ & $y_{1}$ & $y_{2}$ & $y_{3}$ \\
\hline 1 & 0.35 & 0.33 & 0.28 & 4.00 & 2.33 & 3.50 \\
\hline 2 & 0.19 & 0.30 & 0.22 & 3.40 & 4.50 & 3.80 \\
\hline 3 & 0.33 & 0.22 & 0.25 & 3.00 & 3.60 & 3.40 \\
\hline 4 & 0.27 & 0.22 & 0.18 & 4.90 & 3.50 & 3.50 \\
\hline 5 & 0.41 & 0.34 & 0.27 & 3.33 & 4.60 & 4.50 \\
\hline 6 & 0.32 & 0.31 & 0.27 & 3.75 & 4.60 & 4.66 \\
\hline 7 & 0.22 & 0.19 & 0.23 & 4.63 & 4.17 & 4.75 \\
\hline 8 & 0.51 & 0.32 & 0.41 & 4.50 & 4.99 & 5.20 \\
\hline 9 & 0.36 & 0.31 & 0.29 & 5.75 & 5.00 & 5.50 \\
\hline 10 & 0.38 & 0.42 & 0.57 & 5.03 & 5.92 & 5.87 \\
\hline 11 & 0.39 & 0.45 & 0.38 & 5.65 & 5.86 & 6.33 \\
\hline 12 & 0.45 & 0.41 & 0.59 & 5.50 & 6.88 & 5.57 \\
\hline 13 & 0.67 & 0.45 & 0.55 & 4.30 & 6.50 & 5.33 \\
\hline 14 & 0.54 & 0.65 & 0.46 & 5.94 & 6.52 & 6.37 \\
\hline 15 & 0.66 & 0.57 & 0.41 & 5.37 & 6.53 & 6.55 \\
\hline 16 & 0.94 & 0.75 & 0.88 & 6.40 & 6.83 & 6.00 \\
\hline 17 & 0.86 & 0.66 & 0.77 & 6.31 & 6.68 & 6.30 \\
\hline 18 & 0.88 & 0.78 & 0.67 & 6.60 & 6.50 & 6.98 \\
\hline 19 & 0.65 & 0.59 & 0.87 & 6.87 & 6.89 & 7.50 \\
\hline 20 & 0.73 & 0.88 & 0.62 & 7.22 & 6.94 & 7.22 \\
\hline 21 & 0.87 & 0.71 & 0.66 & 7.44 & 6.89 & 7.16 \\
\hline 22 & 0.95 & 0.89 & 0.88 & 7.01 & 7.81 & 7.30 \\
\hline 23 & 0.89 & 0.87 & 0.77 & 7.75 & 8.20 & 9.83 \\
\hline 24 & 0.74 & 0.68 & 0.98 & 8.87 & 9.20 & 9.58 \\
\hline 25 & 1.23 & 1.75 & 1.51 & 8.96 & 8.85 & 9.40 \\
\hline 26 & 1.20 & 1.55 & 1.30 & 9.10 & 9.40 & 9.19 \\
\hline 27 & 1.33 & 1.45 & 1.60 & 9.85 & 9.87 & 9.40 \\
\hline
\end{tabular}

Results of the confirmation experiment for $\mathrm{S} / \mathrm{N}$ ratios values.

\begin{tabular}{lcr}
\hline & Experiment & Prediction \\
\hline & The kerf taper & $\mathrm{X}_{13}, \mathrm{X}_{23}$ \\
Optimal level & $\mathrm{X}_{13}, \mathrm{X}_{23}$ & -47.944 \\
Kerf taper S/N ratio (dB) & -48.893 & $\mathrm{X}_{11}$ \\
Optimal level & Surface roughness & -133.565 \\
\hline
\end{tabular}

Results of the confirmation experiment for mean values.

\begin{tabular}{lcc}
\hline & Experiment & Prediction \\
\hline & Kerf taper & $\mathrm{X}_{11}, \mathrm{X}_{21}, \mathrm{X}_{43}$ \\
Optimal Level & $\mathrm{X}_{11}, \mathrm{X}_{21}, \mathrm{X}_{43}$ & 1.67397 \\
The kerf taper mean values & 1.70611 & $\mathrm{X}_{11}, \mathrm{X}_{21}$ \\
& Surface roughness & 15.068 \\
\hline
\end{tabular}


Results of the confirmation experiment for standard deviation values.

Experiment

Prediction

Optimal level

Kerf taper

$\mathrm{X}_{11}, \mathrm{X}_{43}$

0.0125

$\mathrm{X}_{11}, \mathrm{X}_{43}$

The kerf taper standard deviation

0.0363

Optimal level

Surface roughness

Surface roughness standard deviation

$$
\mathrm{X}_{23}
$$

$\mathrm{X}_{23}$

$-0.140$

$-0.114$

